\title{
On the timing of moulting processes in reproductively active Northern krill Meganyctiphanes norvegica
}

\begin{abstract}
The interactions between moult phasing, growth and environmental cues in Northern krill (Meganyctiphanes norvegica) were examined through analysing populations at seasonal, weekly, and daily timescales. The analyses were carried out on resident populations of krill found in three different neritic locations that experience similar environmental signals (the Clyde Sea, Scotland; the Kattegat, Denmark; Gullmarsfjord, Sweden). Seasonal analyses were carried out on the Clyde Sea population and showed that moulting frequency increased significantly moving from winter to summer. The proportion of moulting females in summer samples was often more than double the proportion of moulting males, suggesting that females had a comparatively shorter intermoult period (IMP). Weekly samples taken from the Kattegat showed a similar pattern. However, although the difference between the proportion of female and male moulters was significant in one week, it was not another, mainly because of the variability in the proportion of female moulters. Such variability in females was equally evident in the daily samples taken at Gullmarsfjord. It suggests that females have a shorter IMP (12.5 days) than males (18.4 days) and are more likely to moult in synchrony. Nevertheless, the daily samples revealed that males are also capable of moult synchronisation, although less frequently than females. Shortened IMPs in females were not a result of the abbreviation of specific moult stages. Accordingly, reproductive activity did not alter the course of the normal moult cycle. There was no
\end{abstract}

Communicated by O. Kinne, Oldendorf/Luhe

C. M. Buchholz $(\bowtie) \cdot$ F. Buchholz

Biologische Anstalt Helgoland - AWI, Meeresstation,

Postfach 180, 27483 Helgoland, Germany

E-mail: cbuchholz@awi-bremerhaven.de

Tel.: + 49-4725-819232

Fax: + 49-4725-819283

G. A. Tarling

British Antarctic Survey, Natural Environment Research Council, High Cross, Madingley Rd, Cambridge CB3 0ET, UK significant difference between the total body lengths of males and females indicating that females achieve the same levels of growth despite moulting more frequently and having to provision the energy-rich ovaries. This is in contrast to most other crustaceans where the energy costs of reproduction reduce female growth. The fact that females were less abundant than males, probably by suffering a greater level of mortality, suggests that different behavioural strategies, particularly vertical migration regimes, were adopted by each sex to maximise growth and reproduction.

\section{Introduction}

The moult cycle is a major part of the life history of all crustaceans, since the exoskeletons must be shed to enable growth. Accordingly, natural selection will select for the optimal patterns of moulting at each principle phase in the life cycle. Many studies have come to the conclusion that, in crustacean species with indeterminate growth, only major physiological processes like maturation and the release of eggs can delay moulting. Consequently, the timing of many other internal processes and behavioural activities is probably dictated by the phasing of the moult cycle both in the short- (days to weeks) and long-term (months to seasons; Hartnoll 1982, 2001; Conan 1985).

The eucarid crustacean, Northern krill (Meganyctiphanes norvegica) is an abundant micro-nectonic species that is a major plankton grazer and a staple food for a large variety of predators, from fish to whales (De Lafontaine et al. 1991; Kaartvedt et al. 2005). Several studies have pointed to the importance of moult phasing in its life history. For instance, reproductive processes such as egg maturation and spawning have been found to be coupled to the moult cycle (Cuzin-Roudy and Buchholz 1999). Moreover, there is a close coordination with vertical migration behaviour, in that moulting occurs in the deep and spawning in the top layer of the 
water column (Tarling et al. 1999). Mass moulting and spawning peaks have been observed, indicating that these processes can be synchronised (Hamner et al. 1983; Buchholz 1985; Tarling and Cuzin-Roudy 2003). Local plankton blooms may act as a cue for initiating investment in ovarian tissue and so may entrain moult and spawn cycles for the rest of the productive season (Tarling and Cuzin-Roudy 2003).

At certain periods, growth is not possible for $M$. norvegica, because nutritional conditions are unfavourable or temperature is too low. Nevertheless, the species still moults and takes the risk of becoming temporarily vulnerable. When this occurs during the productive season (spring to autumn) moulting may still be necessary to facilitate brood maturation and fertilisation (Cuzin-Roudy and Buchholz 1999), as has been reported for other orders of crustaceans (Hartnoll 1985). Moulting behaviour during the winter period has been looked at in Northern krill (Buchholz 1985) and has been intensively studied in the Antarctic krill Euphausia superba (Quetin et al. 2003). The occurrence of moults during a period when there is little or no somatic growth and no reproductive activity suggests that the requirement of this species to shed its exoskeleton with regularity through its life cycle is driven by additional processes that are not yet fully identified.

Comparative analysis is a major biological tool for identifying underlying biological processes. It is apparent that processes operating at a variety of temporal scales (some seasonal, others in the order of days to weeks) influence moult patterns in this species. Some of the processes, particularly the coupling with ovarian development, will affect just one sex or maturity stage. Comparing how moulting patterns alter between males and females at a variety of temporal scales is likely to provide insight into the role of moult phasing in the life history of this species.

The present investigation is based on three separate studies conducted at three different locations where resident populations of krill occur. All the locations have certain features common to neritic regions in the North Atlantic sector, such as a spring phytoplankton bloom and stratification of the water column during the summer. The sites were studied at different temporal scales; the Clyde Sea every other month; the Kattegat, on different weeks during mid summer and Gullmarsfjord, almost every day for a $\sim 2$ week period during late summer. The moult stages of individuals were examined at each site with a precision that depended on the scale of the study. Larger scale studies were based on a simple determination of moult phases (i.e. individuals were classified as "moult" or "non-moult") while studies with finer temporal resolution used a more sophisticated staging system in which the moult cycle was divided into seven stages (Buchholz 1991; Cuzin-Roudy and Buchholz 1999). Overall, our comparative approach provided a powerful means with which to examine the role of moulting in the life history of krill.

\section{Materials and methods}

\section{Basis of data acquisition}

An essential method applied to obtain the data for the present publication was the determination of moult stages. The detailed histological staging was done by F. Buchholz, who adapted Drach's moult staging system for euphausiids (Buchholz 1982), expanded and verified it through parallel determination of the moult hormone titer (Buchholz 1991). The standard procedure of moult staging starts with the observation of cuticle soft- or hardness. With the experience of several thousand detailed stagings the decision of "flaccid" meaning "moulting" = directly before or after ecdysis and "hard" meaning "not close to ecdysis" could safely be ventured.

Only with this background could the simplified method be validated: specimens were taken between the first three fingers of the hand and gently squeezed. If the cuticle was completely compressible and the animal's posture was "flaccid" it was categorised as "moulting".

This flaccid phase corresponded to moult stages $\mathrm{D} 3_{\text {late }}$ (phase of cuticle resorption prior to moult, soft exoskeleton) and A (recently moulted, cuticle very soft) combined. Further details are in Cuzin-Roudy and Buchholz (1999).

The latter determination, being much faster than the histological method, enabled examination of a far larger number of krill. Therefore the other authors learned the distinctions from F. Buchholz serving as standard on several common research cruises. Cross calibration was frequent and determinations in case of doubt verified by histological reference.

\section{Clyde Sea}

Seven sampling campaigns were carried out at 2monthly intervals between June 1999 and May 2000 along a fixed transect NE of the island of Arran in the Clyde sea, West Scotland $\left(55.8^{\circ} \mathrm{N}, 5.2^{\circ} \mathrm{W}\right)$. A multi opening and closing net with environmental sensing system (MOCNESS, $1 \mathrm{~m}^{2}$ net opening, $2 \mathrm{~mm}$ mesh, Wiebe et al. 1985) was deployed over the course of the day and night during each of the campaigns. Further details on the sampling protocols can be found in Tarling and Cuzin-Roudy (2003). In the present study, we pooled all of the net catches within a campaign to obtain an estimate of the relative frequency of moulting individuals every other month over an annual cycle (June, August, October, December 1999 and January, March, May 2000).

Approximately 200 live krill per sample were sexed, measured for total body length (front of the eye to the tip of the telson) and staged in categories "moulting" or "non-moulting" according to the rigidity of the exoskeleton. 


\section{Kattegat}

Net samples (MOCNESS, see above) were taken in the Alkor deep, east of the Danish Island Läsö in the Northern Kattegat $\left(57.3^{\circ} \mathrm{N} 11.4^{\circ} \mathrm{E}\right.$, further details in Tarling et al. 1999). The net was deployed at cardinal times of the day $(05: 00,14: 00,22: 00,02: 00)$ in a depth discrete fashion (100-80, 80-65, 65-50, 50-30 and 30$5 \mathrm{~m}$ ) between 24 July and 26 July 1998 and between 30 July and 3 August 1998. The freshly caught krill were classified as either "moulting" or "non-moulting" using the same protocol as above. Statistical analyses were carried out on depth-integrated estimates of moult-frequency (i.e. through pooling samples) and also on discrete depth layers. In particular, the nature of the sampling regime allowed us to examine the proportion of moulting animals in the deep layers at night-time, which previous studies have identified as being the main habitat of krill during moulting (Lasker 1966; Fowler et al. 1971; Tarling et al. 1999). Statistical analyses were mainly focused on examining the differences in the moult frequency between the 2 weeks of sampling.

\section{Gullmarsfjord}

The moult activity of $M$. norvegica was analysed in Gullmarsfjord $\left(58.3^{\circ} \mathrm{N}, 11.5^{\circ} \mathrm{E}\right)$ between August 15 th and 30th, 2000. The duration of the study was set such that it covered the likely length of a complete intermoult period (IMP) which, according to Cuzin-Roudy and Buchholz (1999), is around 13 days at an average temperature of $7^{\circ} \mathrm{C}$. Samples were taken with an Isaacs Kidd Midwater Trawl $\left(0.6 \mathrm{~m}^{2}\right.$ net opening, $1.5 \mathrm{~mm}$ mesh) every week day around noon from August 16 to September 1, 2000, concentrating at a depth of 80 $100 \mathrm{~m}$ where krill were found to reside. Three further deployments were made around midnight, at the start, the middle and the end of the sampling campaign in which samples were taken from two depth-layers: 0-40 and $60-100 \mathrm{~m}$.

A randomly taken sub-section of the live krill, 60 krill per sample (total $N=840 \mathrm{krill}$ ), were subjected to detailed analysis: they were sexed, length measured and staged for moult (MS) and sexual development stages (SDS according to Cuzin-Roudy and Buchholz 1999, data not shown). The remainder of the krill were classified as either "moulting" or "non-moulting", using "touch" analysis in a similar fashion to that carried out in the Clyde Sea and Kattegat.

Detailed moult stages were determined by viewing the uropod integument under a light microscope and categorising it into one of the seven main moult stages A to D3. These are listed below along with their expected proportions in a random population, which has been refined from the values in Cuzin-Roudy and Buchholz (1999) based on additional data acquired since by the same authors (unpublished data). These proportions are equivalent to the relative amount of time it takes an individual to pass through this stage in the moult cycle:

- Postmoult:

A (2.0\% duration of IMP), B (7.4\%), C (21.1\%),

- Premoult:

D0 (15.6\%), D1 (23.4\%), D2 (18.2\%), D3 (12.7\%).

Direct observations at a water temperature of $10^{\circ} \mathrm{C}$ revealed the complete IMP as being 13 days (CuzinRoudy and Buchholz 1999). There is a physiological necessity to proceed through the stages directly adjoining ecdysis (D3, A) in a fast, perfectly scheduled manner in order to reduce the dangers of hampered swimming ability lacking rigid muscle attachments or hardening of the shell before its shedding is completed. The duration of moult stages D3 and A $(12.7+2 \%)$ is therefore considered fixed, meaning that $M$. norvegica spend 1.9 days "moulting" or "moult active."

According to Cuzin-Roudy and Buchholz (1999), the duration of the IMP, (days) of an unknown field population can be assessed using the formula:

$\operatorname{IMP}(d)=\frac{1.9}{\% \mathrm{D} 3+A} \times 100$,

where 1.9 is the number of days individuals remain within a temporally fixed "moult active" stage (updated value) and $\% \mathrm{D} 3+A$ is the percentage of individuals encountered in moult stage D3 or A.

However, in the Gullmarsfjord campaign it was necessary to make some modifications to the classification because there was a time delay of $8-12 \mathrm{~h}$ between capture and moult-analysis that did not occur at the other study sites. The animals were maintained in the dark in cooled and aerated seawater during this time. As a result, cuticle hardening occurred in freshly moulted animals while others preparing for moult started to become flaccid. We adapted the "moulting" category to include flaccid krill along with those that were hardening (A and B) or softening specimens (D3 $3_{\text {early }}$ ). Each of these states could still be identified by finger touch taking the rigidity of the anterior rim of carapace and its frontal spines as criteria.

Accommodating stage B in the assessment, because of the time delays in analysis described above, a new value of 2.9 days was defined as the duration of the "moult active" stage comprising D3, A and B. The new assessment of IMP was accordingly:

$\operatorname{IMP}(d)=\frac{2.9}{\% \mathrm{D} 3+A+B} \times 100$.

\section{Results}

Taken over the three locations, a total of $18,783 \mathrm{krill}$ were analysed for moult stage. Additional determination 
of SDS on females confirmed reproductive activity in all three populations (Tarling et al. 1999; Tarling and Cuzin-Roudy 2003; C.M. Buchholz and F. Buchholz, unpublished). To maximise the resolution of the moult patterns, Table 1 focuses on the moulting krill encountered at night in the deep in summer. Failures in the depth-discrete sampling system in the Clyde Sea during summer meant that only depth integrated samples were collected in this location at that time. This probably underestimates the relative proportion of krill in moult, because most of the non-moulting fraction can be expected in the higher strata of the water column (Tarling et al. 1999). Nevertheless, we found that the proportion of female moulters was about three times that of males in each of the three locations (Table 1). Depth-discrete samples taken in the deeper layers during the night consistently contained more males than females, with female:male sex ratios ranging from 1:2 to 1:10.

\section{Seasonal patterns in moulting activity}

Overall, a greater proportion of the population in the Clyde Sea were found to be in moulting condition during the spring and summer months (March/May and June/August) compared with the winter (Fig. 1), which infers that individuals moulted more frequently during the productive season. However, there was a marked difference in the seasonal patterns exhibited by females compared with that of males. In the former, between 15 and $23 \%$ of the population were in moulting condition during the summer months, whereas only $6-11 \%$ were moulting in the latter. By contrast, there was little difference in the proportion of female and male moulters observed during the autumn and winter (October; December/January), since both dropped to low levels $(<6 \%)$ in this period. A one-way ANOVA found there was a significant difference in the proportion of female moulters between seasons (Kruskall-Wallis: $H_{2}=6.675, P=0.036$ ) but not in

Table 1 The proportion of female and male moulting individuals in the populations sampled between dusk and dawn in the Clyde Sea, Kattegat and Gullmarsfjord

\begin{tabular}{lcll}
\hline & $\begin{array}{l}\text { Clyde }^{\mathrm{a}} \\
\text { Jun/Aug } \\
\end{array}$ & $\begin{array}{l}\text { Kattegat }^{\mathrm{b}} \\
\text { Jul/Aug } \\
1999\end{array}$ & $\begin{array}{l}\text { Gullmarn }^{\mathrm{b}} \\
\text { Aug } \\
298\end{array}$ \\
\hline No. of females & 321 & 408 & 19 \\
Moulting females & 76 & 258 & 11 \\
\% Moulting fem. & 23.7 & 63.2 & 57.9 \\
No. of males & 816 & 680 & 161 \\
Moulting males & 66 & 144 & 27 \\
\% Moulting males & 8.1 & 21.2 & 16.8 \\
Sex ratio f/m & 0.4 & 0.6 & 0.1 \\
Proportion & & & \\
\% Moult. fem/\% moult. male & 2.9 & 3.0 & 3.5 \\
\hline
\end{tabular}

\footnotetext{
${ }^{\mathrm{a}}$ Depth integrated data

${ }^{\mathrm{b}}$ Deepest stratum $(80-100 \mathrm{~m})$
}

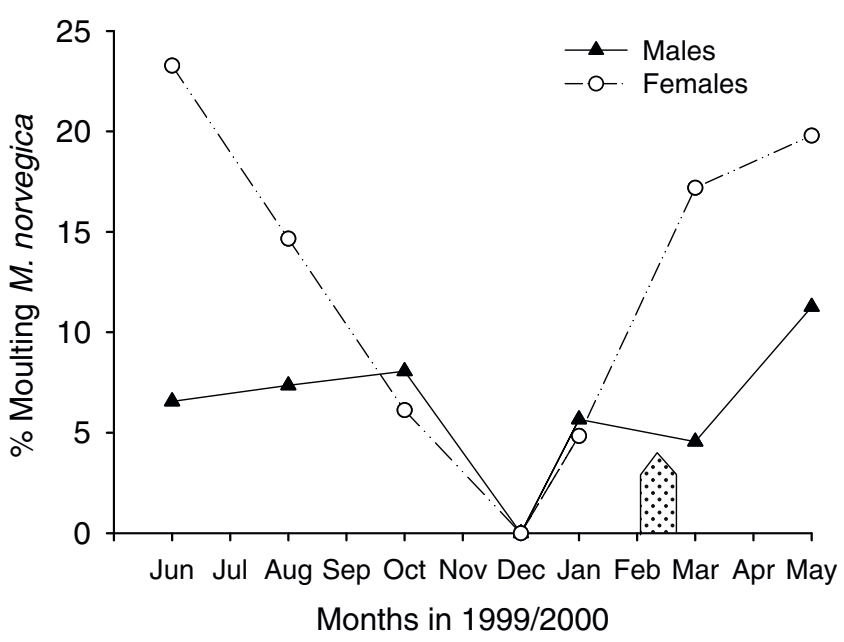

Fig. 1 Daily percentage of male and female Meganyctiphanes norvegica in moulting condition over an annual cycle (June 1999May 2000) in the Clyde Sea. The dotted area above the abscissa indicates the period of a phytoplankton bloom. Moulting condition was scored by touching the freshly caught animals $(N=1,137)$ for cuticle softness

males $\left(F_{35,2}=0.680, P=0.513\right)$, which reflects the fact that the proportion of male moulters increased only marginally during the productive months. Different statistical tests were used for males and females because of the different distributions of the data. The female data failed a normality test, so it was necessary to use a non-parametric test (Kruskall-Wallis). The male data passed a normality test, so it was more appropriate to use a parametric test (which is statistically more powerful). The fact that the less powerful non-parametric test still found a significant difference in the females indicates that the differences in these data was large. In males, the situation is converse.

Weekly to daily patterns in moulting activity

A similar pattern is seen at a weekly timescale in the Kattegat. As with the Clyde Sea seasonal study, the overall proportion of female moulters was greater than that of males, indicating that females moulted more frequently. However, statistical analysis of all data showed significant variation in the observed proportion of female moulters between weeks $\left(t_{12,16}=2.515\right.$, $P=0.018, \quad N=7,518$ ), with proportions reaching around $23 \%$ (SD 13\%) in week 1 compared with just $13 \%(\mathrm{SD} 8 \%)$ in week 3 . The percentage difference between male moulters in weeks 1 and 3 was less, being $17 \%(\mathrm{SD} 7 \%$ ) in week 1 and $11 \%(\mathrm{SD} 6 \%$ ) in week 3 , and non-significant $\quad\left(t_{12,16}=2.047, \quad P=0.051\right.$, $N=5,492)$. The pattern is more pronounced in the deep samples during night-time (Fig. 2; Table 1) given that this is the most common habitat for moulters according to previous studies. In the midnight sample (Fig. 2), 87\% (SD 8\%) of female $M$. norvegica were 


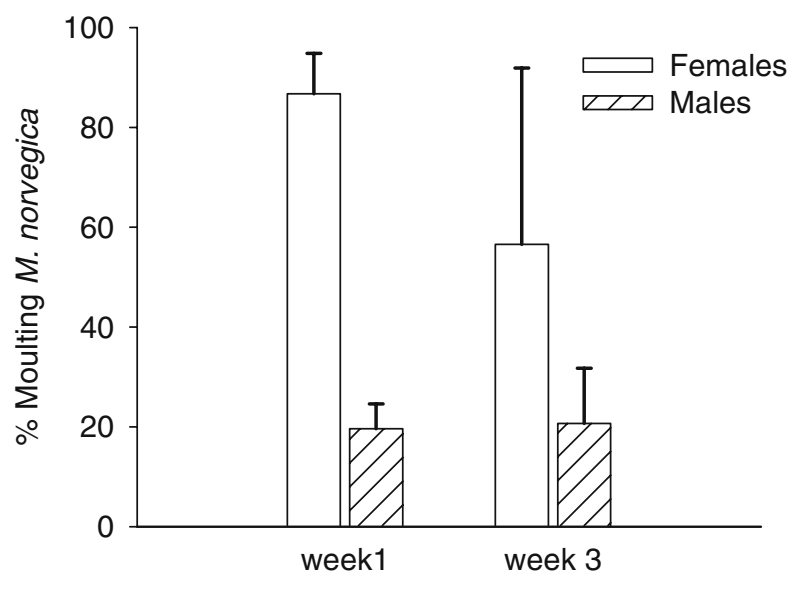

Fig. 2 Weekly percentage of male and female $M$. norvegica in moulting condition from deep (80-100 m), mid-night (02:00) catches in the Kattegat. Week 1 comprised three nights of data (24th to 26th July), week 3 four nights of data (31st July to 3rd August). Moulting condition was scored by touching the freshly caught animals $(N=402)$ for cuticle softness

found moulting in week 1 and $57 \%$ (SD 35\%) in week 3 , while only $20 \%$ of males were moulting in each of the weeks. The data suggest that females can be synchronised and moult in pulses while males seem to moult in a more random manner relative to each other.

The variation in the proportion of moulters over time was examined at a much higher temporal frequency in Gullmarsfjord. The period of study covered more than the duration of a typical IMP in this species so that any pulses in moulting at the population level would be resolved. At a random distribution of moult stages $22 \%$ of the krill would be expected moulting (D3, A and B). Yet in the females, two peaks in moulting were observed at the start and end of the study period, in which up to 30 and $40 \%$ of the population located in the deeper layers at night were moulting (Fig. 3). Between these two periods, there was a trough in moulting activity where the proportion was between 5 and $12 \%$. A oneway ANOVA found a significant difference in the proportion of female moulters between these periods (period $1=15-18$ Aug; period $2=21-25$ Aug; period $3=28-30 \quad$ Aug; $\quad$ Kruskall-Wallis: $H_{2}=5.628$, $P=0.047)$. In contrast to the females, a relatively low proportion of male moulters was observed during the start of the study and this continued through the middle period. However, as with the females, the proportion of male moulters rose above $22 \%$ towards the end of the study reaching levels in excess of $30 \%$ of the deep population. This proportion of moulters was significantly different to the levels observed in the previous periods $\left(F_{8,2}=12.178, P=0.004\right)$. It can be surmised that males as well as females are capable of pulses in moulting, although such pulses occur less frequently in the former compared with the latter. The pattern also suggests that the IMP of males is longer than that of females.

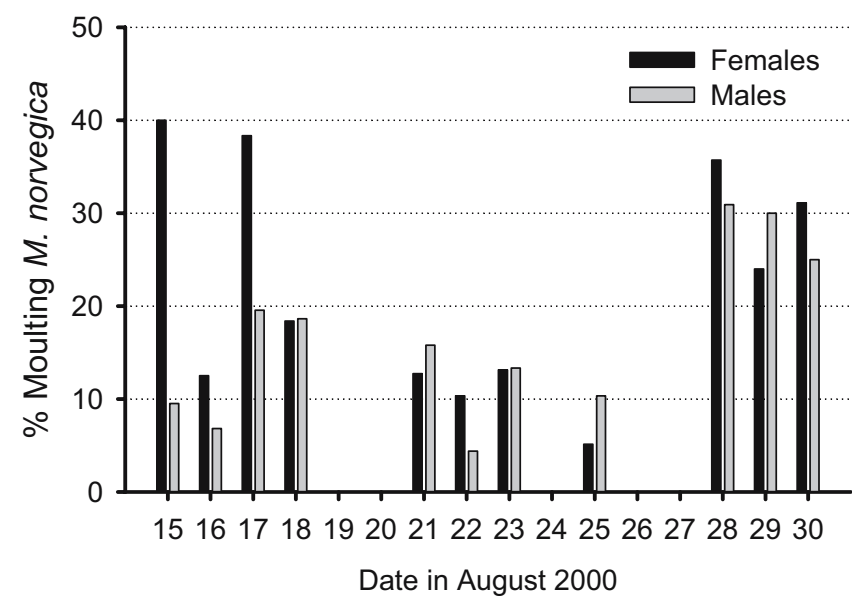

Fig. 3 Daily percentage of male and female $M$. norvegica in moulting condition in Gullmarsfjord. Moulting animals were those that were either soft in "touch" analysis or were classified as being in stages $\mathrm{D}_{3}, \mathrm{~A}, \mathrm{~B}$ in detailed analyses ( $N$ analysed in "touch" analysis $=882, N$ in detailed histological analysis $=840$ )

\section{Intermoult period and growth}

The detailed analyses of moult stages carried out on the Gullmarsfjord population presented further insights into IMP and its corresponding influence on growth. The data allowed us to ask three further questions: (1) what is the predicted IMP for males and females; (2) is there any difference in the relative duration of the seven distinct phases of the moult cycle between males and females; (3) is the difference in the IMP between females and males reflected in somatic growth and does it result in the sexes having different body sizes.

Our calculations using Eq. 2 found that there was a 6-day difference in the IMP of males and females, with females taking around 12.5 days to complete their moult cycle and males 18.4 days (Table 2). This finding agrees with the apparent trends in the other two locations, where the proportion of female moulters was consistently higher than that of males. The relative lengthening of the IMP is not the product of the increase in the relative length of any one particular moult stage (Fig. 4). Both males and females spent the majority of their respective IMPs in either stage $C$ (intermoult) or stage D2 (premoult). The largest differences between the sexes appeared to be in stages A and B, which were relatively

Table 2 Calculation of the intermoult period (IMP) of female and male krill in Gullmarsfjord using information from detailed moult stages and applying Eq. 2

\begin{tabular}{|c|c|c|c|c|}
\hline & $\begin{array}{l}\text { Detailed } \\
\text { MS of } N\end{array}$ & $\begin{array}{l}\text { Number } \\
\text { in MS } \\
\text { D3 + A + B }\end{array}$ & $\begin{array}{l}\% \\
\text { in } \mathrm{MS} \\
\mathrm{D} 3+\mathrm{A}+\mathrm{B}\end{array}$ & $\begin{array}{l}\text { IMP } \\
\text { (days) }\end{array}$ \\
\hline Females & 245 & 57 & 23 & 12.5 \\
\hline Males & 595 & 94 & 16 & 18.4 \\
\hline All & 840 & 151 & 39 & 16.1 \\
\hline
\end{tabular}




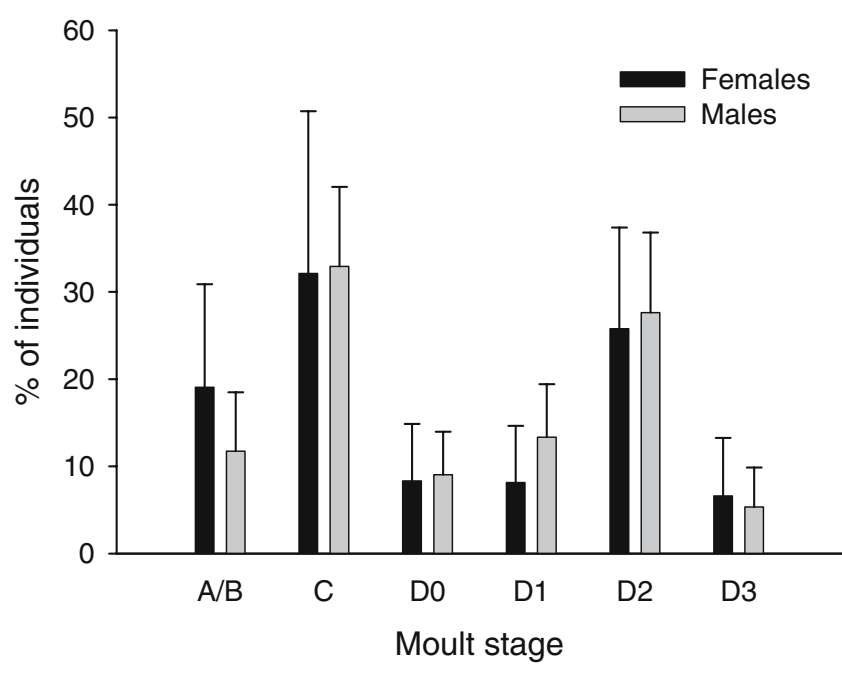

Fig. 4 Percentage of female and male krill in different moult stages at Gullmarsfjord between 15th and 30th August 2000. Value of the columns indicates the average $\%$ of the population in that moult stage over all samples within this time period. Error bars indicate 1 $\mathrm{SD}$

longer in females and D1, which was longer in males. However, neither of these moult stage durations were significantly different between females and males.

The length-frequency distributions of both females and males sampled in Gullmarsfjord were unimodal and had modal lengths of 38.1 and $38.0 \mathrm{~mm}$, respectively (Fig. 5). It is highly probable that the female and male fractions are the same age class and that they were spawned in the previous year (1999). The distributions were not significantly different at the $P<0.05$ levels. Similarly, there was no significant difference in the average size of female and male krill in each of the individual catches, although there was a pattern in several catches of females being around $1 \mathrm{~mm}$ longer than males. This lack of difference in mean body lengths implies that there is no difference in the somatic growth rates of females and males. It also means that, given that males have longer IMPs than females, their growth increment per moult must be relatively larger.

\section{Discussion}

In this study, we found that moulting frequencies in Northern krill alter dramatically with season, reaching their peak during the summer months and falling to considerably lower levels during the winter period. This pattern was most pronounced in the females with males never achieving equivalently high moulting levels during the summer. The proportion of female moulters observed in samples was also more variable than that of males, suggesting that females were more likely to exhibit synchronised moulting behaviour. Even so, there were indications that such behaviour may also occur in males. In all three study sites, the average proportion of female moulters was consistently higher than that of males, indicating that females had a shorter IMP. Calculations based on moult stage analysis estimated that the difference could be as much as 6 days, with females moulting every 12.5 days and males every 18.4 days. Despite this difference, the body lengths of males and females were similar indicating that variations in IMP did not affect their respective growth rates. However, such variations may be a contributory factor in the apparent difference in the respective mortality rates, since males were more abundant than females in all three study sites.

\section{Seasonal patterns in moulting activity}

Our observations on the decrease of moulting frequency during the winter months agree with those of Buchholz (1985) who found rates in M. norvegica in the Kattegat were greatly reduced between September and November. Ikeda and Thomas (1987) found a similar situation in E. superba, where females extended their IMP after the final spawn of the season. As reviewed by Conan (1985), it has long been known that crustaceans display a certain "periodicity and phasing" in their patterns of moulting and growth. Regional as well as seasonal differences have been observed between and within species. The variations are directly or indirectly influenced by temperature regimes and other environmental conditions like photoperiod or food availability (Conan 1985).
Fig. 5 a Length-frequency distribution of the female and male fractions of the Gullmarsfjord population pooled from all samples between 15th and 30th August 2000. b Average size of female and male $M$. norvegica in each of the samples taken in Gullmarsfjord in August 2000 (females $N=245$, males $N=595$ ). Bars indicate $1 \mathrm{SD}$
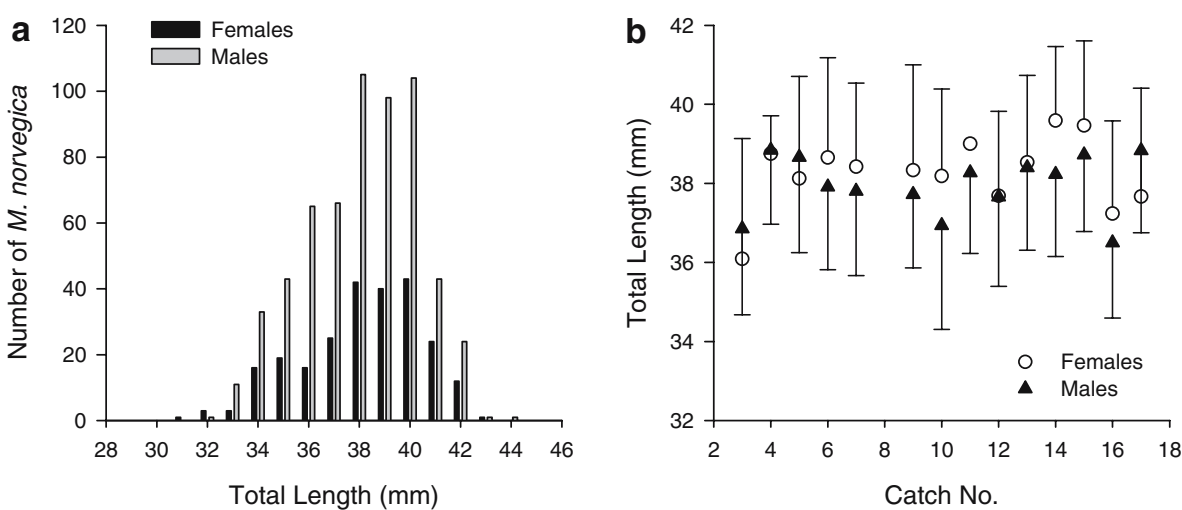
Crustacean physiological processes are adapted to specific temperature windows, in which rising temperatures generally result in shortened IMP and minimum temperatures (thresholds) must be exceeded before egg production can commence (Hartnoll 1982, 2001). The relatively small seasonal difference in temperatures (3$4^{\circ} \mathrm{C}$ ) in the Clyde Sea may well account for the limited changes in moulting frequency of males, but is unlikely to be the only factor affecting female IMPs, which changed more dramatically over the course of the seasons. Hormonal cascades triggered by other seasonally changing parameters such as food availability and light periodicity are potential mechanisms for facilitating such changes to moulting frequencies.

Weekly to daily patterns in moulting activity

Our results from both the Kattegat and Gullmarsfjord studies indicate that there is a moult synchrony in the populations and that this is more likely to be evident in the females than in the males. This pattern was also observed by Anderson et al. (1985) for the free spawning, penaeoid shrimp Sicyonia ingentis with the moult synchrony of the females being more pronounced and longer lasting than that of males. The low number of moulting $M$. norvegica on the 16 August were probably caused by a "fishing effect", the net missing the deep area where moulters concentrate. It has long been known that swarms are not homogenous in all parts (Buchholz et al. 1996). Statistical analysis nevertheless ascertained significant differences between the three periods compared.

Tarling and Cuzin-Roudy (2003) demonstrated that synchronised moult and reproductive cycles of female $M$. norvegica can be initiated by spring phytoplankton blooms. A similar induction of synchronous moulting clearly triggered by a food pulse had formerly been reported for the anomuran Emerita analoga (Siegel 1984). Synchronous moulting has also been observed in the larvae of $M$. norvegica (Schmidt et al. 2004) although the processes that initiated the pattern were not investigated.

Concerning daily patterns, moulting at night-time is a frequent behaviour not only in euphausiids (Lasker 1966; Fowler et al. 1971) but also other crustaceans (Conan 1985). A depth discrete study on $M$. norvegica showed that the majority of moulting krill remains in the deep layers of the water column during the night-time while the rest of the population migrate to the surface layers (Tarling et al. 1999). Therefore differential moulting behaviour can best be elucidated by examining deep night samples.

Intermoult period and growth

\section{Intermoult period of females and males}

We identified conspicuous sex dependent differences in moulting at all three locations and at different time scales. Not only did sexual maturation result in a synchronisation of moulting in females, it also increased their moult frequency compared to that of males, at least temporarily. The dissimilarities between the sexes can be seen in the seasonal study of the Clyde Sea (Fig. 1), on the weekly scale of the Kattegat study (Fig. 2) and in the daily data of the study at Gullmarsfjord (Tables 1, 2), the latter in terms of both the ratios of moulting females/ moulting males and the estimated IMP. Buchholz et al. (1996) found that E. superba continued moulting during the breeding period, with gravid females having a longer IMP (13 days) than mature males ( 8 days) of a similar body length. Females moulted more frequently again after the production and spawning of eggs had ceased. Tarling et al. (2006), by contrast, concluded that immature and mature female E. superba moult more often than equivalently sized mature males. The potential bias resulting from the levels of synchronisation in the swarms may account for the difference between the studies. Tarling et al. (2006) were able to eliminate this bias of synchronisation through applying logistic regressions to the combined dataset of $\sim 50$ swarms.

We calculated that IMP was 12.5 days for females and 18.4 days for males during the Gullmarsfjord study. The IMP model of Cuzin-Roudy and Buchholz (1999) predicts an IMP of $\sim 13$ days at the temperatures that prevailed during the present study, which is closer to the female rate. By contrast, Cuzin-Roudy et al. (2004) used an incubation method to determine the IMP of krill in the same location at the same time of year, and came to a value of between 16 and 18 days. Cuzin-Roudy et al. (2004) did not differentiate between males and females in their IMP calculation, although some of their other data show that males dominated the population $(\geq 2: 1)$. The fact that their IMP estimate of a male dominated population is close to our prediction of male IMP illustrates the robustness of the various methods of estimating this parameter.

\section{The body length of males and females}

Our observation that males and females do not differ significantly in body length indicates that males achieve the same growth rate as females despite their lower moulting frequency. We are confident that both sexes are the same age, since they were the same size as in the population study of Boysen and Buchholz (1984) and in the Clyde Sea study of Tarling (2003) when cohorts were followed over a complete annual cycle. This means that growth increments (GIs) at moult must be different between sexes. Laboratory experiments on $M$. norvegica, aimed at the determination of growth increments have, up to now, yielded very ambiguous results with increments varying between positive and negative values and means being close to zero (Cuzin-Roudy et al. 2004 and own observations). Unluckily, $M$. norvegica are much more sensitive to maintenance in the laboratory than other euphausiids. 
Increasing body size has distinct advantages for krill. There is a well documented positive correlation between body size and brood size (Mauchline and Fischer 1969; Mauchline 1980; Cuzin-Roudy 2000) enhancing the overall reproductive success. Furthermore, larger krill are able to generate a larger momentum (Thomasson et al. 2003) and so cover greater distances when foraging for food, which is notoriously patchy. This greater swimming capacity also allows the krill to migrate vertically at greater speeds. In the case of females, vertical migration into the warm surface waters at night may not only allow foraging in the most food-rich layers but may also enable the brood of eggs to develop at a greater rate (Tarling et al. 1999). Females appear to spend more time than males in the upper layers (Tarling 2003 and own observations). It may be through this means that they obtain enough food to avoid the allocation conflict between growth and reproduction that could affect the relative growth rates of males and females in crustaceans (Hartnoll 1985; Conan 1985). However, high feeding rates are achieved at the cost of greater exposure to predation risk (Tarling 2003). This may explain why, as a rule, numbers of females are smaller than those of males. This trend was not found in the Kattegat data of the present study. However, Boysen and Buchholz (1984), who carried out an annual study of the Kattegat population, found a majority of males in 9 out of 11 samples, showing that our Kattegat data is very much an exception to the general rule.

\section{Moult stage durations}

The shortened IMP of female krill could have been a result of particular abbreviated moult stages in comparison to those in male krill of the same population. Statistical pairwise comparisons of the data in Fig. 4 do not support such a contention, the frequency of moult stages differing little between males and females. This means that all moult stages are equally abbreviated in female krill and so reproductive activity does not substantially alter the course of the normal moult cycle.

We identified moult stages $\mathrm{C}$ and D2 as having the longest durations, as is common in other crustaceans (e.g. Nelson 1991; Cuzin-Roudy and Buchholz 1999). Differences in the length of the moult cycle in other crustaceans most commonly occur through altering the duration of these stages, particularly when entering a resting or anecdysic period. Both stages mark the end of important phases. In $\mathrm{C}$, the postmoult phase comes to an end when the new cuticle is completed and body reserves have been re-plenished; the next premoult phase can then be triggered. In D2, cuticle resorption has ended and the new cuticle underneath the old one is ready for initiation of the next actual moult. The fact that the relative duration of these moult stages is invariant in Northern krill indicates that the species never enters a true resting stage, as already demonstrated for Antarctic krill by Buchholz (1985). Please note that the difference in proportions of krill occurring in the respective moult stages (Fig. 4) to those given in material and methods for a random distribution results from the Gullmarn population being synchronised as discussed before.

\section{Selective advantages of moulting}

Our studies show that female moult intervals are $\sim 30 \%$ shorter than those of males but that their net increase in body length is the same. The difference indicates that the rate of moulting must be dictated by other selective pressures in addition to that of the requirement to grow. One possibility is that there is a pressure to remate regularly to ensure the efficient fertilization of eggs. Krill mate by attaching their spermatophores to the female thelycum, thereby facilitating fertilization by placing a sperm plug at the aperture that eggs must pass through during spawning (Mauchline and Fisher 1969). Females lose their spermatophores at each moult and new spermatophores are attached by neighbouring males immediately after moulting. Spawning takes place just after reaching moult stage D0, which is around $2 / 3$ of the way through the moult cycle (Cuzin-Roudy and Buchholz 1999). If the moult cycle is too long, the delay between spermatophore attachment and spawn may be too long for fertilization to be efficient. The female may be under a selective pressure to moult more frequently to minimise this time interval. Alternatively, the linkage between the moult and spawn cycles may mean that speeding up the moult cycle allows more mating and spawning events and thus, more genetic combinations to be achieved per season. The males would not be affected by such selective pressures and so will have a longer IMP that is energetically less costly and results in the animal being flaccid and vulnerable less often.

Although selective pressures associated to reproduction can account for the differences between the rate of moulting in males and females, it remains difficult to explain why moulting continues to take place at all outside the reproductive season, when somatic growth is also negligible. The selective pressure here may be to minimise the level of parasitism. Recent observations on endoparasitic ciliates in euphausiids report devastating mortality that could impact whole swarms (GomezGutierrez et al. 2003; see also Capriulo et al. 1991). Epibionts could also impose non-lethal effects on krill through imposing additional drag on these fast swimming animals. One such parasite, the ellobiopsid Thalassomyces fagei, both creates drag and may inhibit processes such as moulting and reproduction through castrating its host (Mauchline 1980). Another group of epibionts, ciliates of the genus Ephelota, attach to the filtering basket of E. superba and impair its proper function (Lindley 1978; Nicol 1984; Stankovic et al. 2002). Regular shedding of the cuticle reduces the problem through removing these ectoparasites. Infestation of larger euphausiids with longer IMPs has been 
found to be higher (Nicol 1984; Rakusa-Suszczewski and Filcek 1988).

If the effect of these ectoparasites is to reduce swimming efficiency substantially, one may expect a trade-off between moulting and non-moulting. Individuals that moult frequently increase their vulnerability through being flaccid for almost 2 days and being less capable of swimming (Thomasson et al. 2003), but benefit from enduring less drag from ectoparasites. Individuals that moult less frequently endure greater drag but have a proportionally greater time in an active swimming state. For females, swimming efficiency may be the priority since they make more extensive vertical migrations and also must locate a greater number of food patches to provision their energy-rich ovaries (Tarling et al. 2003). Males may otherwise benefit from remaining active for as long as possible so that they miss less opportunities to mate with the females. Future studies comparing levels of ectoparasite counts on males and females should be one means of testing this hypothesis.

Acknowledgements The hospitality and efficient support at Kristineberg Marine Research Station and the kind help of Jalle Strömberg are gratefully acknowledged. The scientific and ship's crew of FS "Heincke" contributed substantially to the sampling in the Kattegat, as well as those on RV "Calanus" in the Clyde Sea and on RV "Oskar von Sydow" in the Gullmarsfjord. Janine Cuzin is thanked for her eager interest in our work and hours of discussion. The work was supported by grants from the Transnational Access funds to KMRS and EU-MAST III (MAS3-CT95-0013), "The PEP Programme." Fieldwork in the Clyde, carried out by GT, was funded by a NERC postdoctoral fellowship (GST/ 59818MS). GT's contribution to the data analysis was carried out as part of the FLEXICON project of the DISCOVERY 2010 programme at BAS. We wish to express our gratitude to three anonymous advisors who spent their time and consideration to help us improve the manuscript.

\section{References}

Anderson SL, Wallis HC, Chang ES (1985) Multiple spawning and molt synchrony in a free spawning shrimp (Sicyonia ingentis: Penaeoidea). Biol Bull 168:377-394

Boysen E, Buchholz F (1984) Meganyctiphanes norvegica in the Kattegat. Studies on the development of a pelagic population. Mar Biol 79:195-207

Buchholz F (1982) Drach's molt staging system adapted for euphausiids. Mar Biol 66:301-305

Buchholz F (1985) Moult and growth in euphausiids. In: Siegfried WR, Condy P, Laws RM (eds) Antarctic nutrient cycles and food webs. Springer, Berlin Heidelberg New York, pp 339-345

Buchholz F (1991) Moult cycle and growth of Antarctic krill, Euphausia superba, in the laboratory. Mar Ecol Prog Ser 69:217-229

Buchholz F, Watkins JL, Priddle J, Morris DJ, Ricketts C (1996) Moult in relation to some aspects of reproduction and growth in swarms of Antarctic krill, Euphausia superba. Mar Biol 127:201-208

Capriulo GM, Pedone MJ, Small EB (1991) High apostome ciliate endoparasite infection rates found in the Bering Sea euphausiid Thysanoessa inermis. Mar Ecol Prog Ser 72:203-204

Conan GY (1985) Periodicity and phasing of molting. In: Schram FA, Wenner AM (eds) Crustacean Issues 3. A. A. Balkema, Rotterdam, pp 73-99
Cuzin-Roudy J (2000) Seasonal reproduction, multiple spawning, and fecundity in northern krill, Meganyctiphanes norvegica, and Antarctic krill, Euphausia superba. Can J Fish Aquat Sci 57:6-15

Cuzin-Roudy J, Buchholz F (1999) Ovarian development and spawning in relation to the moult cycle in Northern krill, Meganyctiphanes norvegica (Crustacea: Euphausiacea), along a climatic gradient. Mar Biol 133:267-281

Cuzin-Roudy J, Tarling GA, Strömberg J-O (2004) Life cycle strategies of Northern krill (Meganyctiphanes norvegica) for regulating growth, moult, and reproductive activity in various environments: the case of fjordic populations. ICES J Mar Sci 61:721-737

De Lafontaine Y, Demers S, Runge J (1991) Pelagic food web interactions and productivity in the Gulf of St Lawrence: A perspective. In: J-C. Therriault (ed) The Gulf of St. Lawrence: small ocean or big estuary? NRC Research Press, Ottawa, Canada, pp 99-123

Fowler SW, Small LF, Keckeš S (1971) Effects of temperature and size on molting of euphausiid crustaceans. Mar Biol 11:45-51

Gomez-Gutierrez J, Peterson WT, De Robertis A, Brodeur RD (2003) Mass mortality of krill caused by parasitoid ciliates. Science 301:339

Hamner WM, Hamner PP, Strand SW, Gilmer RW (1983) Behavior of Antarctic krill, Euphausia superba: chemoreception, feeding, schooling, and molting. Science (Washington) 220:433435

Hartnoll RG (1982) Growth. In: Bliss DE, Abele LG (eds) The biology of crustacea, vol 2. Academic, New York, pp 111-196

Hartnoll RG (1985) Growth, sexual maturity and reproductive output. In: Schram FA, Wenner AM (eds) Crustacean Issues 3. A.A. Balkema, Rotterdam, pp 101-128

Hartnoll RG (2001) Growth in Crustacea-twenty years on. Hydrobiologia 449:111-122

Ikeda T, Thomas PG (1987) Moulting interval and growth of juvenile Antarctic krill (Euphausia superba) fed different concentrations of the diatom Phaeodactylum tricornutum in the laboratory. Polar Biol 7: 339-343

Kaartvedt S, Rostad A, Fiksen O, Melle W, Torgersen T, TisethBreien M, Klevjer TA (2005) Piscovorous fish patrol krill swarms. Mar Ecol Prog Ser 299:1-5

Lasker R (1966) Feeding, growth, respiration, and carbon utilization of a euphausiid crustacean. J Fish Res Board Can 23:12911317

Lindley JA (1978) Continuous plankton records: the occurrence of apostome ciliates (Protozoa) on Euphausiacea in the North Atlantic Ocean and North Sea. Mar Biol 46:131-136

Mauchline J (1980) The biology of mysids and euphausiids. Academic, London, New York, Toronto, Sydney, San Francisco

Mauchline J, Fischer LR (1969) The biology of euphausiids. Academic, London, New York

Nelson K (1991) Scheduling of reproduction in relation to molting and growth in malacostracan crustaceans. In: Schram FA, Wenner AW, Kuris A (eds) Crustacean Issues 7. A. A. Balkema, Rotterdam, Brookfield, pp 77-113

Nicol S (1984) Ephelota sp., a suctorian found on the euphausiid Meganyctiphanes norvegica. Can J Zool 62:744-745

Quetin LB, Ross RM, Frazer TK, Amsler MO, Wyatt Evens C, Oakes SA (2003) Growth of larval krill, Euphausia superba, in fall and winter West of the Antarctic Peninsula. Mar Biol 143:833-843

Rakusa-Suszczewski S, Filcek K (1988) Protozoa on the body of Euphausia superba Dana from Admiralty Bay (the South Shetland Islands). Acta Protozool 27:21-30

Schmidt K, Tarling GA, Plathner N, Atkinson A (2004) Moult cycle-related changes in feeding rates of larval krill Meganyctiphanes norvegica and Thysanoessa spp. Mar Ecol Prog Ser 281:131-143

Siegel PR (1984) Food-induced size-specific molt synchrony of the sand crab, Emerita analoga (Stimpson). Biol Bull 167:579-589

Stankovic A, Borsuk P, Koper M, Weglenski P (2002) Studies on Ephelota sp., an epizoic suctorian found on Antarctic krill. Polar Biol 25:827-832 
Tarling G (2003) Sex-dependent diel vertical migration in northern krill Meganyctiphanes norvegica and its consequences for population dynamics. Mar Ecol Prog Ser 260:173-188

Tarling GA, Cuzin-Roudy J (2003) Synchronization in the molting and spawning activity of Northern krill (Meganyctiphanes norvegica) and its effect on recruitment. Limnol Oceanogr 48:2020-2033

Tarling GA, Cuzin-Roudy J, Buchholz F (1999) Vertical migration behaviour in the Northern krill Meganyctiphanes norvegica is influenced by moult and reproductive processes. Mar Ecol Prog Ser 190:253-262

Tarling GA, Shreeve RS, Hirst AG, Atkinson A, Pond DW, Murphy EJ, Watkins JL (2006) Natural growth rates in Ant- arctic krill (Euphausia superba): I. Improving methodology and predicting intermolt period. Limnol Oceanogr 51:959-972

Thomasson MA, Johnson ML, Strömberg J-O, Gaten E (2003) Swimming capacity and pleopod beat rate as a function of sex, size and moult stage in Northern krill Meganyctiphanes norvegica. Mar Ecol Prog Ser 250:205-213

Wiebe PH, Morton AW, Bradley AM, Craddock JE, Cowles TJ, Barber VA, Backus RH, Flierli GR (1985) New developments in the MOCNESS, an apparatus for sampling zooplankton and micronekton. Mar Biol 87:313-323 